\section{The BDJ news page}

The BDJ accepts all general news items that might interest our readers. Press releases or articles should not exceed $\mathbf{5 0 0}$ words and may be edited. Please include a colour photograph if possible. As space for photographs is limited, priority will be to given to good quality and/or interesting pictures. Please send BDJ news items to Kate Craig.

\section{Ribena still tooth kind, says BDA}

The BDA has challenged the Advertising Standards Authority's ruling against Ribena ToothKind, a product accredited by the Association.

In its decision, the ASA said that the claim that 'Ribena ToothKind does not encourage tooth decay' was misleading. The BDA disagrees and says its view is backed up by 1200 pages of peer-reviewed research data.

The BDA continue to support fully the dental health claims made for Ribena ToothKind and validated by its Food and Drinks Accreditation Panel. SmithKline Beecham has been granted permission of the Court to apply for judicial review of the ASA's decision.

Dr Geoff Craig, Chair of the BDA's Health and Science Committee, said:

\title{
Picture perfect
}

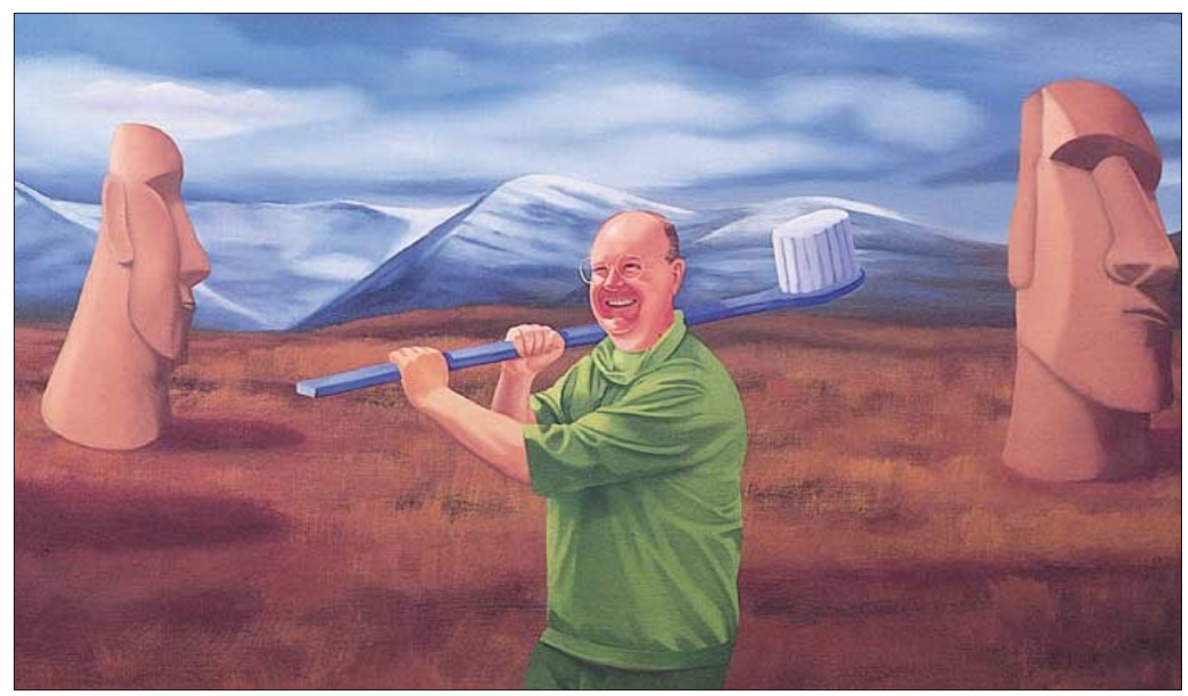

This painting of dentist Mr Eilerston of Dingwall, Scotland, was produced on commission by his patient, Michael Forbes.

'The ASA's decision will not affect the BDA's support for a soft drink that dentists can recommend with confidence.'

\section{Specsavers on hold}

Specsavers, the market leaders in optics, has put dentistry plans on hold after a thorough investgation of prospects in the dentistry market, and has decided instead to concentrate on its expansion plans for international and UK optics.

The group's dental business development director Tony Langham and his colleague

\section{Investors in Hampshire}

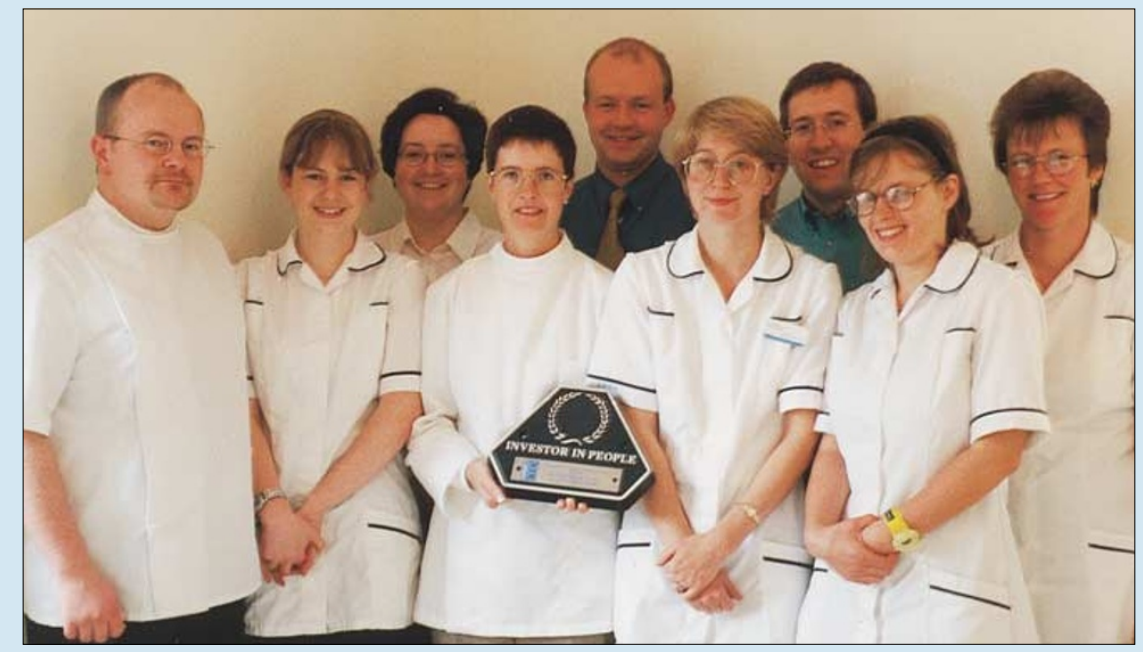

Hamish Morton (far left) and his team from Birchfield Dental Practice in Hampshire celebrate after being recognised as an Investor in People.
Stuart Chidgey have purchased in a management buyout the dental body corporate and the three practices in Devon and Wiltshire which Specsavers had acquired as part of its market analysis. The enterprise will be run as community dental centres.

\section{First female president for BDTA}

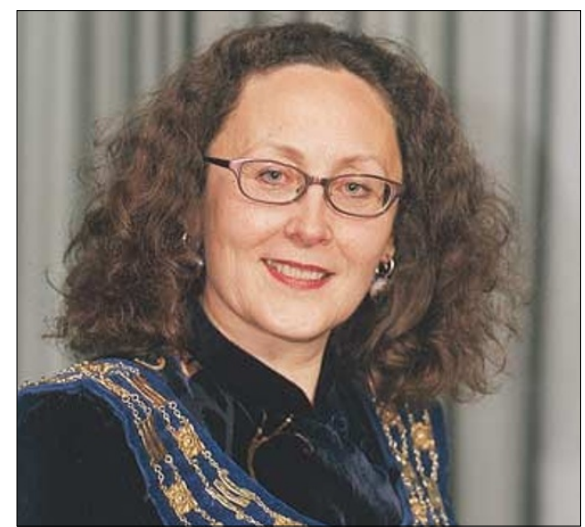

Ann Sterry has been elected as the first female president in the 76 year history of the British Dental Trade Organisation.

Ann took over from Mr Brian Schottlander at the Association's Annual conference in Gloucester in July.

Ann works as European Director of Colgate Oral Pharmaceuticals and has won the backing of her company to support her during her year of office with the Association.

'It will be a busy schedule,' says Ann, 'but I am looking forward to the challenge.' 